\title{
Solar Thermochemical Reactions IV: Unusual Reaction of Nitrones with Acetonitrile Derivatives Induced by Solar Thermal Energy
}

\author{
Ramadan Ahmed Mekheimer ${ }^{1 *}$, Khadijah Mohamed Al-Zaydi ${ }^{1}$, Asma Al-Shamary ${ }^{1}$, \\ Kamal Usef Sadek ${ }^{2}$ \\ ${ }^{1}$ Department of Chemistry, Faculty of Science for Girls, King Abdul-Aziz University, Jeddah, Kingdom of Saudi Arabia \\ ${ }^{2}$ Chemistry Department, Faculty of Science, El-Minia University, El-Minia, AR Egypt \\ E-mail: rmekh@yahoo.com \\ Received June 13, 2011; revised July 15, 2011; accepted July 28, 2011
}

\begin{abstract}
The behaviour of cyanothioacetamide 1 and the acetonitrile derivatives $\mathbf{6}$ and 10, respectively, towards the nitrones 2a-i induced by free solar thermal energy is reported. Structures and reaction mechanisms are also discussed.
\end{abstract}

Keywords: Nitrones, Cyanothioacetamide, 2-(Hetaryl)Acetonitrile Derivatives, Synthesis, Solar Thermal Energy

\section{Introduction}

Nitrones are used as useful reagents or intermediates in the synthesis of a variety of nitrogen-containing compounds which find application as agro-chemicals and/or pharmaceuticals [1]. Generally, nitrones easily undergo 1,3-dipolar cycloaddition reactions with a large variety of substituted alkenes including both electron-rich and electron-poor dipolarophiles [2,3]. The resulting fivemembered isoxazolidine derivatives may be converted into amino alcohols, precursors to biologically important amino acids, alkaloids or $\beta$-lactams [4-8]. In addition to the well-known cycloaddition chemistry of nitrones, there are several reports on nucleophilic addictions to nitrones promoted and/or catalyzed by Lewis acids [9-11].

Recently, we have designed a new strategy aiming at the synthesis of pharmacologically interesting heterocyclic systems using solar energy as eco-friendly energy source [12-14]. In continuation of this work, we report herein the behaviour of some acetonitrile derivatives towards differently substituted open-chain $C$-aryl(or hetaryl)$\mathrm{N}$-phenylnitrones under the effect of solar thermal energy. To the best of our knowledge, the use of free solar thermal energy to accomplish such study has not so far been reported in the literature.

\section{Results and Discussion}

The reactions between cyanothioacetamide 1 with the nitrones 2 were first investigated. Thus, the reaction of cyanothioacetamide 1a, which is completely enthiolized in liquid phase (Figure 1), with the diphenylnitrone 2a in absolute ethanol under solar heating for $2 \mathrm{~h}$ (TLC control) did not afford 5-amino-5-mercapto-2,3-diphenylisoxazolidine-4-carbonitrile 3a, as a final product, but furnished instead the unexpected 2-cyano-3-phenylprop-2enethioamide 5a, in good yield (Scheme 1). Although the synthesis of arylmethylenecyanothioacetamide derivatives has been reported [15-18], compound 5a was not previously isolated as a solid and always generated in situ. Therefore, it seems to be very interesting to report the first isolation of 2-cyano-3-phenylprop-2-enethioamide 5a. The structure of 5a was assigned on the basis of consistent elemental and spectral data. Thus, the IR spectrum showed the presence of absorption bands at

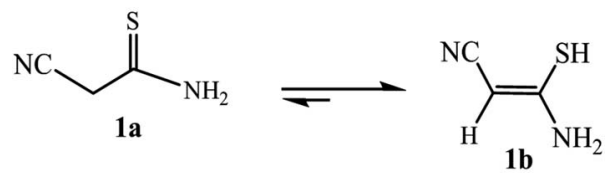

Figure 1. The equilibrium between cyanothioacetamide (1a) and 3-amino-3-mercapto-acrylonitrile (1b). 


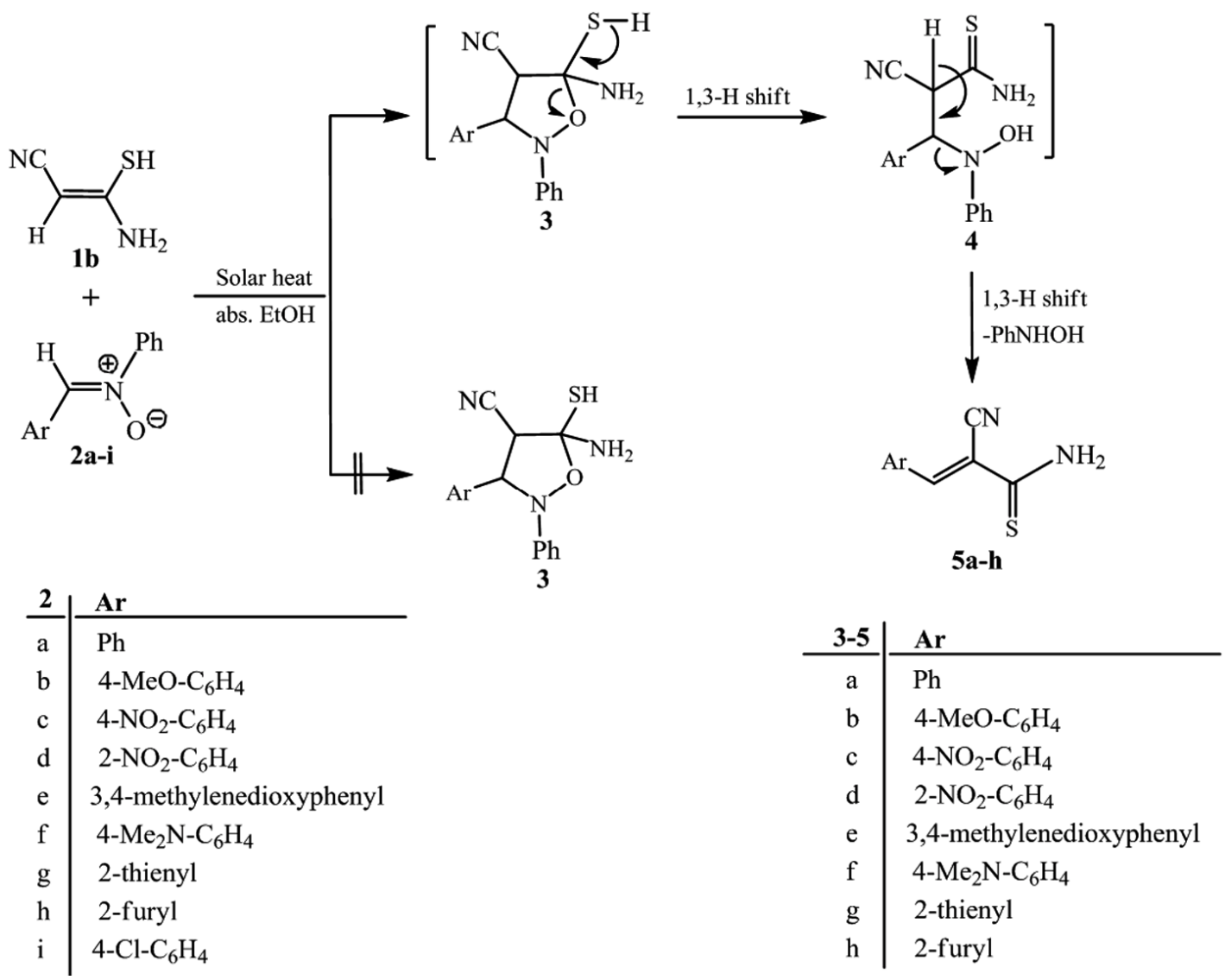

Scheme 1. Synthetic route used for preparing the 3-aryl-2-cyanothio-acrylamides 5a-h from nitrones and cyanothioacetamide and proposed mechanism for their synthesis.<smiles>C#CCCCCCCN1C(S)=NN/C1=C/C#N</smiles>

Figure 2. The equilibrium between 2-(5-ethylthio-4-phenyl4H-1,2,4-triazol-3-yl)acetonitrile (6a) and 2-(3-ethylthio-4phenyl-1H-1,2,4-triazol-5(4H)-ylidene)acetonitrile (6b).

$3400 \mathrm{~cm}^{-1}, 3300 \mathrm{~cm}^{-1}, 3200 \mathrm{~cm}^{-1}$ and $2220 \mathrm{~cm}^{-1}$ assignable to $\mathrm{NH}_{2}$ and $\mathrm{CN}$ functions, while the ${ }^{1} \mathrm{H}$ NMR spectrum contained two singlet signals at $7.95 \mathrm{ppm}$ and 9.57 ppm, attributable to the olefinic proton and the thioamide protons respectively, in addition to five aromatic protons at $7.43 \mathrm{ppm}-7.61 \mathrm{ppm}$. Furthermore, its structure was supported by ${ }^{13} \mathrm{C}$ NMR, MS and analytical data analysis which confirmed the proposed structure. Formation of $5 \mathbf{a}$ could be achieved by an initial 1,3-dipolar cycloaddition of the nitrone $\mathbf{2 a}$ and compound $\mathbf{1 b}$ giving the isoxazolidines intermediate $\mathbf{3}$. This adduct undergoes an internal proton shift and ring-opening to yield a further intermediate 4 which then undergoes a proton shift and carbon-nitrogen fission to afford the final product $\mathbf{5 a}$
(Scheme 1).

The generality of the method is demonstrated by using different $C$-aryl (or hetaryl)- $N$-phenylnitrones. Thus, reaction of $\mathbf{1 b}$ with $\mathbf{2} \mathbf{b}-\mathbf{h}$ under the same reaction conditions gave the corresponding 3-aryl-2-cyanothio-acrylamides 5b-h. Their structures were confirmed by comparison of their physical properties (mp, mixed mp, IR, ${ }^{1} \mathrm{H}$ NMR) with those of authentic samples prepared as previously described [15].

To develop this reaction into a more general method, other acetonitrile derivatives, containing a heterocyclic sub-structure at position 2 , were also tried. Thus, the reaction of 2-(5-ethylthio-4-phenyl-4H-1,2,4-triazol-3-yl)acetonitrile $\mathbf{6 b}$ (Figure 2), with the nitrones 2a,b,i gave the corresponding derivatives 9a-c (Scheme 2). The compound 9a thus obtained was identical in all respects (mp, mixed mp, IR, ${ }^{1} \mathrm{H}$ NMR) with that previously prepared by Mekheimer et al. [19]. The structures of 9b,c were deduced from their IR, NMR and correct elemental analyses as well as mass spectra. Thus, the IR spectra of $\mathbf{9 b}, \mathbf{c}$ revealed the presence of absorption band at 2220 $\mathrm{cm}^{-1}$ due to cyano function. The ${ }^{1} \mathrm{H}$ NMR spectra contained a singlet signal at $7.88 \mathrm{ppm}$ and $8.45 \mathrm{ppm}$ assign- 
able to the olefinic proton in $\mathbf{9 b}$ and $\mathbf{9 c}$, respectively, in addition to signals due to ethyl, phenyl and aryl protons. Additionally, their structures were supported by ${ }^{13} \mathrm{C}$ NMR and correct mass spectra and analytical data, which were all compatible with the assigned structures (see Experimental). The formation of 9a-c may take place through an initial 1,3-dipolar cycloaddition of 2 to the olefinic $\pi$ bond of $\mathbf{6 b}$ to yield the spiro intermediate 7 which was converted to 9 by a similar mechanism to that discussed above for the formation of 5 (see Scheme 2).

Other acetonitriles derivatives in which the 2-position is substituted with benzothiazole moiety were also used. Thus, the nitrones $\mathbf{2 a}, \mathbf{b}, \mathbf{i}$ reacted with 2-(benzo-thiazol-
2(3H)-ylidene)acetonitrile 10b, under the same reaction conditions, to afford 3-aryl-2-(benzothiazol-2-yl)acrylonitrile derivatives 11a-c (Scheme 3), presumably by a mechanism similar to that discussed above for the formation of 9. The structures of the benzothiazole derivatives 11a-c were established by comparison with authentic samples (mp, mixed mp, IR, ${ }^{1} \mathrm{H}$ NMR) prepared as previously reported [20].

In order to investigate the exact effect of solar energy in accelerating the reaction whether it is a thermal or a photochemical one, we carried out the reaction in dark under conventional heating and for the same reaction time. It afforded the same products obtained under solar

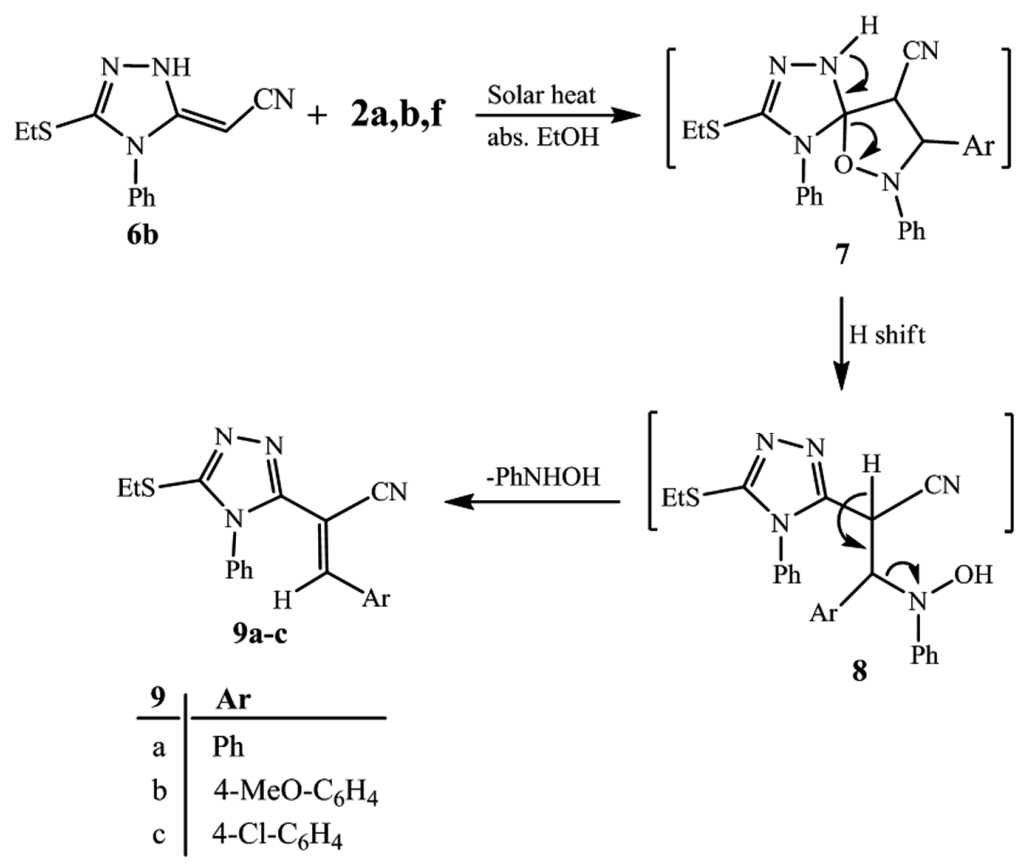

Scheme 2. Synthetic route used for preparing the 3-aryl-2-(5-ethylthio-4-phenyl-4H-1,2,4-triazol-3-yl)acrylonitrile 9a-c from nitrones 2a,b,f and 2-(3-ethylthio-4-phenyl-1H-1,2,4-triazol-5(4H)-ylidene)acetonitrile (6b) and proposed mechanism for their synthesis.

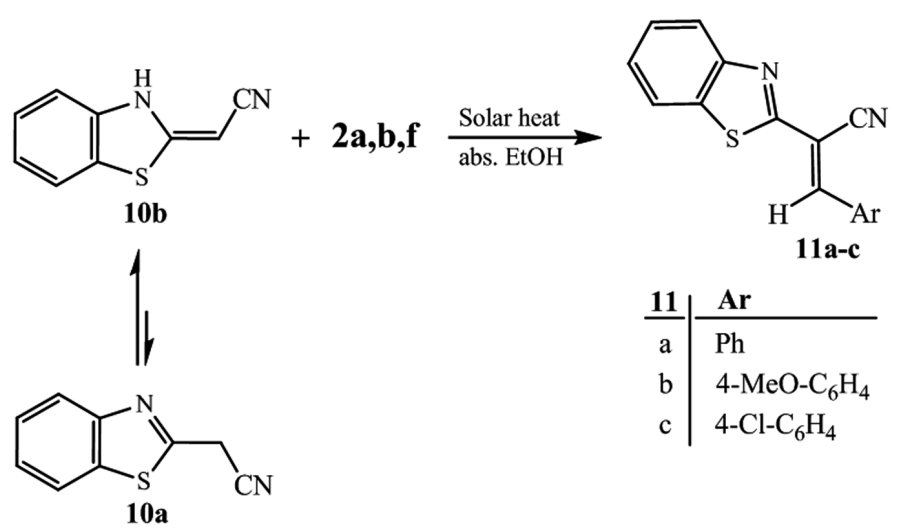

Scheme 3. Synthetic route used for preparing the 3-aryl-2-(benzothiazol-2-yl)acrylonitrile derivatives 11a-c from nitrones 2a,b,f and 2-(benzothiazol-2(3H)-ylidene)acetonitrile (10b). 
energy. At the same time, we performed the same reaction at a low temperature $\left(10^{\circ} \mathrm{C}\right)$ under the effect of artificial visible light and the reactants were recovered, unchanged even when exposure was performed for a longer reaction time. This rules out the possibility of a photochemical reaction.

\section{Conclusions}

In this fourth-generation version of our strategy, we have shown that the reaction between nitrones and some acetonitrile derivatives under solar heating efficiently leads the unexpected 3-aryl-2-cyanothioacrylamide and 3-aryl2-(hetaryl)acrylonitrile derivatives. The significant advantages of this procedure are green, high yields, a simple work-up procedure. Further studies in our laboratory aimed at the synthesis of new heterocyclic ring systems induced by solar thermal energy are now in progress and will be published in due course.

\section{Experimental}

\subsection{General}

Melting points were measured on a Gallenkamp apparatus and were not corrected. IR spectra were recorded with a Nicollet Magna 520FT IR spectrophotometer.
Peaks are reported in $\mathrm{cm}^{-1} \cdot{ }^{1} \mathrm{H}$ and ${ }^{13} \mathrm{C}$ NMR spectra were recorded on a Bruker DPX $\left(600 \mathrm{MHz}\right.$ for ${ }^{1} \mathrm{H}$ NMR and $150 \mathrm{MHz}$ for ${ }^{13} \mathrm{C} \mathrm{NMR}$ ) spectrometer in DMSO- $d_{6}$ using TMS as an internal standard; the chemical shifts are given in $\delta$ units (ppm). Mass spectra were measured on a GCMS-QP1000EX mass spectrometer. Analytical thin-layer chromatography (TLC) was performed on aluminum sheets precoated with silica gel (Merck, Kieselgel 60F-254). Visualization was accomplished by UV light. Micro-analyses were performed at the Microanalytical Data Unit at Cairo University.

\subsection{Synthesis of 3-Aryl-2-cyanothioacrylamides 5a-h, General Procedure}

To a solution of cyanothioacetamide (1) (2.5 mmole) in absolute EtOH (10 mL), nitrones 2a-h (2.5 mmole) were added. Then, the reaction mixture was exposed to direct sunlight for 1-3 h, until the TLC showed the disappearance of the starting materials. The maximum temperature of the reaction mixture was determined and cited in Table 1. The excess of solvent was removed in vacuo. The resulting solid product was collected by filtration and recrystallized from EtOH to yield 5a-h. The products 5b-h were characterized by IR, NMR and through comparison of their physical properties with those reported in literature.

Table 1. Solar thermal energy synthesis of 3-aryl-2-cyanothioacrylamides 5a-h and 3-aryl-2-(hetaryl)acrylonitrile derivatives 9a-c and 11a-c.

\begin{tabular}{|c|c|c|c|c|c|c|}
\hline Product & Ar & Time (h) & Yield (\%) & M. P. $\left({ }^{\circ} \mathbf{C}\right)$ & Lit. M. P. $\left({ }^{\circ} \mathrm{C}\right)$ & Maximum reaction temperature $\left({ }^{\circ} \mathrm{C}\right)$ \\
\hline $5 a$ & $\mathrm{Ph}$ & 2 & 63 & $145-147$ & - & 53 \\
\hline $5 \mathbf{b}$ & $4-\mathrm{MeOC}_{6} \mathrm{H}_{4}$ & 2 & 73 & $189-190$ & $190-191^{15}$ & 48 \\
\hline $5 c$ & $4-\mathrm{NO}_{2} \mathrm{C}_{6} \mathrm{H}_{4}$ & 3 & 69 & $187-188$ & $188-189^{15}$ & 58 \\
\hline $5 d$ & $2-\mathrm{NO}_{2} \mathrm{C}_{6} \mathrm{H}_{4}$ & 5 & 66 & $179-180$ & $180-181^{15}$ & 58 \\
\hline $5 e$ & 3,4-methylenedioxyphenyl & 2 & 67 & $216-217$ & $215-216^{15}$ & 55 \\
\hline $5 f$ & $4-\mathrm{Me}_{2} \mathrm{NC}_{6} \mathrm{H}_{4}$ & 1 & 65 & $229-231$ & $231-232^{15}$ & 57 \\
\hline $5 g$ & 2-thienyl & 3 & 54 & $168-169$ & $169-170^{15}$ & 57 \\
\hline $5 h$ & 2-furyl & 3 & 52 & $156-157$ & $158^{15}$ & 51 \\
\hline $9 a$ & $\mathrm{Ph}$ & 14 & 98 & $149-150$ & $149-150^{19}$ & 56 \\
\hline $9 b$ & $4-\mathrm{MeOC}_{6} \mathrm{H}_{4}$ & 5 & 67 & $172-173$ & - & 58 \\
\hline $9 c$ & 4- $\mathrm{ClC}_{6} \mathrm{H}_{4}$ & 11 & 66 & $169-170$ & - & 59 \\
\hline $11 a$ & $\mathrm{Ph}$ & 6 & 64 & $121-122$ & $121-123^{20}$ & 56 \\
\hline $11 b$ & $4-\mathrm{MeOC}_{6} \mathrm{H}_{4}$ & 4 & 81 & $142-143$ & $143-144^{20}$ & 59 \\
\hline 11c & $4-\mathrm{ClC}_{6} \mathrm{H}_{4}$ & 4 & 73 & $148-150$ & $148-150^{20}$ & 56 \\
\hline
\end{tabular}




\subsection{2-Cyano-3-phenylprop-2-enethioamide (5a)}

${ }^{1} \mathrm{H}$ NMR $\left(600 \mathrm{MHz}\right.$, DMSO-d $\left.\mathrm{d}_{6}\right): \delta=7.43-7.61(\mathrm{~m}, 5 \mathrm{H})$, 7.95 (s, 1H), 9.57 (br s, 2H). ${ }^{13} \mathrm{C}$ NMR $(150 \mathrm{MHz}$, DMSO-d $\left.{ }_{6}\right): \delta=102.2,118.0,128.0,128.4,129.0,129.2$, 129.6, 130.4, 136.5, 195.5. IR (KBr): $v=3410,3295$, $3200,2185,1619 \mathrm{~cm}^{-1}$. Found: C, 63.67; H, 4.37; N, 15.0; S, 16.85; anal. calcd for $\mathrm{C}_{10} \mathrm{H}_{8} \mathrm{~N}_{2} \mathrm{~S}$ : C, 63.80; H, 4.28; N, 14.88; S, 17.03. MS: $m / z=188\left(\mathrm{M}^{+}, 60\right), 187$ $\left(\mathrm{M}^{+}-1,100\right), 172(3), 162(4), 161$ (4), 160 (7), 155 (12), 128 (14), 102 (20), 101 (11), 100 (7), 78 (8), 77 (24), 76 (14), 75 (13), 74 (11), 60 (49), 51 (42), 50 (29).

\subsection{Synthesis of 3-Aryl-2-(hetaryl)acrylonitriles 9a-c and 11a-c; General Procedure}

To a solution of compounds $\mathbf{6}$ or $\mathbf{1 0}$ ( 2.5 mmole $)$ in absolute EtOH $(12 \mathrm{~mL})$, nitrones $\mathbf{2 a}, \mathbf{b}, \mathbf{i}(2.5 \mathrm{mmole})$ were added. The flask was exposed to direct sunlight for a period determined by TLC control (see Table 1). The maximum temperature of the reaction mixture was determined and cited in Table 1. Then, the reaction mixture was worked up as described above for $\mathbf{5 a - h}$ to give the products 9a-c and 11a-c, respectively.

\subsection{2-(5-Ethylthio-4-phenyl-4H-1,2,4-triazol-3-yl)- 3-(4-methoxyphenyl)acrylonitrile (9b)}

${ }^{1} \mathrm{H}$ NMR $\left(600 \mathrm{MHz}, \mathrm{DMSO}-\mathrm{d}_{6}\right): \delta=1.43\left(\mathrm{t},{ }^{3} J=7.2 \mathrm{~Hz}\right.$, $3 \mathrm{H}), 3.28\left(\mathrm{q},{ }^{3} J=7.2 \mathrm{~Hz}, 2 \mathrm{H}\right), 3.86(\mathrm{~s}, 3 \mathrm{H}), 6.93\left(\mathrm{~d},{ }^{3} J=\right.$ $7.8 \mathrm{~Hz}, 2 \mathrm{H}), 6.97(\mathrm{~m}, 1 \mathrm{H}), 7.33(\mathrm{~m}, 2 \mathrm{H}), 7.53(\mathrm{~m}, 1 \mathrm{H})$, $7.58(\mathrm{~m}, 1 \mathrm{H}), 7.82\left(\mathrm{~d},{ }^{3} J=7.8 \mathrm{~Hz}, 2 \mathrm{H}\right), 7.88(\mathrm{~s}, 1 \mathrm{H}) .{ }^{13} \mathrm{C}$ NMR $\left(150 \mathrm{MHz}\right.$, DMSO-d $\left._{6}\right): \delta=14.7,29.7,55.5,93.6$, $114.5,115.1,121.3,127.4,129.0,130.1,132.3,132.7$, 146.3, 149.3, 153.9, 157.6. IR $(\mathrm{KBr}): v=2922,2200$ $\mathrm{cm}^{-1}$. MS: $m / z=362\left(\mathrm{M}^{+}, 12\right), 361(45), 333(7), 118$ (12), 115 (7), 114 (14), 108 (2), 88 (7), 78 (11), 77 (100), 65 (11), 64 (15), 63 (21), 61 (7), 60 (12), 51 (72), 50 (20). Found: C, 66.41; H, 4.89; N, 15.29; S 9.07; anal. calcd for $\mathrm{C}_{20} \mathrm{H}_{18} \mathrm{~N}_{4} \mathrm{OS}$ : C, 66.28; H, 5.01; N, 15.46; S, 8.85.

\subsection{3-(4-Chlorophenyl)-2-(5-ethylthio-4-phenyl-

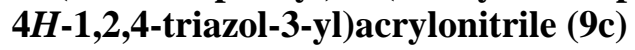

${ }^{1} \mathrm{H}$ NMR $\left(600 \mathrm{MHz}\right.$, DMSO-d 6 ): $\delta=1.43\left(\mathrm{t},{ }^{3} J=7.2 \mathrm{~Hz}\right.$, $3 \mathrm{H}), 4.06\left(\mathrm{q},{ }^{3} J=7.2 \mathrm{~Hz}, 2 \mathrm{H}\right), 6.93(\mathrm{~m}, 2 \mathrm{H}), 7.23(\mathrm{~m}$, $3 \mathrm{H}), 7.44\left(\mathrm{~d},{ }^{3} J=8.4 \mathrm{~Hz}, 2 \mathrm{H}\right), 7.82\left(\mathrm{~d},{ }^{3} J=8.4 \mathrm{~Hz}, 2 \mathrm{H}\right)$, 8.45 (s, 1H). IR: (KBr): $v=3050,2970,2200$. MS: $\mathrm{m} / z=$ $368\left(\mathrm{M}^{+}, 4\right), 366\left(\mathrm{M}^{+}, 8\right), 337$ (9), 255 (3), 244 (2), 230 (2), 189 (3), 161 (5), 137 (7), 126 (9), 118 (10), 113 (3), 112 (3), 105 (9), 100 (5), 99 (9), 91 (12), 77 (99), 65 (22), 64 (12), 63 (17), 61 (10), 60 (19), 59 (24), 51 (100), 50 (28). Found: C, 62.01; H, 4.25; Cl, 9.59; N, 15.38; S,
8.68; anal. calcd for $\mathrm{C}_{19} \mathrm{H}_{15} \mathrm{ClN}_{4} \mathrm{~S}: \mathrm{C}, 62.20 ; \mathrm{H}, 4.12 ; \mathrm{Cl}$, 9.66; N, 15.27; S, 8.74.

\section{Acknowledgements}

The authors are grateful to King Abdul-Aziz University, Jeddah, Kingdom of Saudi Arabia, for the financial support and necessary facilities which enabled this research to be completed.

\section{References}

[1] P. Merino, "Science of Synthesis," In: A. Padwa, D. Bellus, Eds., George-Thieme Verlag, Stuttgart, Vol. 27, 2004, p. 511.

[2] J. J. Tufariello, "1,3-Dipolar Cycloaddition Chemistry," In: A. Padwa, Ed., Wiley, New York, Vol. 2, 1984, p. 83.

[3] A. Padwa and A. M. Schoffstall, "Advances in Cycloaddition," In: D. P. Curran, Ed., JAI Press, Greenwich, Vol. 2, 1990, p. 2.

[4] A. Padwa, "Synthetic Applications of 1, 3-Dipolar Cycloaddition Chemistry toward Heterocycles and Natural Products," In: W. H. Pearson, Ed., Wiley and Sons, Hoboken, 2003, pp. 1-83.

[5] K. V. Gothelf and K. A. JØrgensen, "Asymmetric 1,3Dipolar cycloaddition Reactions," Chemical Reviews, Vol. 98, No. 2, 1998, pp. 863-910. doi:10.1021/cr970324e

[6] M. Frederickson, "Optically Active Isoxazolidines via Asymmetric Cycloaddition Reactions of Nitrones with Alkenes: Applications in Organic Synthesis," Tetrahedron, Vol. 53, No. 2, 1997, pp. 403-425. doi:10.1016/S0040-4020(96)01095-2

[7] J. J. Tufariello, "1, 3-Dipolar Cycloaddition Chemistry," In: A. Padwa, Ed., Wiley and Sons, New York, 1984, pp. 83-167.

[8] U. Chiacchio, A. Rescifina, G. Romeo and O. A. Attanasi, "Targets in Heterocyclic Systems," In: D. Spinelli, Ed., Italian Society of Chemistry, Rome, Vol. 1, 1997, p. 225.

[9] P. Merino, S. Franco, F. L. Merchan and T. Tejero, "Nucleophilic Additions to Chiral Nitrones: New Approaches to Nitrogenated Compounds," Synlett, Vol. 2000, No. 4, 2000, pp. 442-454. doi:10.1055/s-2000-6555

[10] M. Lombardo and C. Trombini, "Nucleophilic Additions to Nitrones," Synthesis, No. 6, 2000, pp. 759-774. doi:10.1055/s-2000-6269

[11] P. Merino, "New Developments in Nucleophilic Additions to Nitrones," Comptes Rendus Chimie, Vol. 8, No. 5, 2005, pp. 775-788. doi:10.1016/j.crci.2005.02.013

[12] R. A. Mekheimer, A. M. Abdel Hameed and K. U. Sadek, "Solar Thermochemical Reactions: Four-Component Synthesis of Polyhydroquinoline Derivatives Induced by Solar Thermal Energy," Green Chemistry, Vol. 10, No. 5, 2008, pp. 592-593. doi:10.1039/b715126h

[13] R. A. Mekheimer, M. A. Ameen and K. U. Sadek, "Solar Thermochemical Reactions II: Synthesis of 2-Amino- 
Thiophenes via Gewald Reaction Induced by Solar Thermal Energy," Chinese Chemical Letters, Vol. 19, No. 7, 2008, pp. 788-790. doi:10.1016/j.cclet.2008.04.041

[14] R. A. Mekheimer, A. M. Abdel Hameed, S. A. A. Mansour and K. U. Sadek, "Solar Thermochemical Reactions III: A Convenient One-Pot Synthesis of 1,2,4,5-Tetrasubstituted Imidazoles Ccatalyzed by High Surface Area $\mathrm{SiO}_{2}$ and Induced by Solar Thermal Energy," Chinese Chemical Letters, Vol. 20, 2009, pp. 812-814. doi:10.1016/j.cclet.2009.02.017

[15] J. S. A. Brunskill, A. De and D. F. Ewing, "Dimerisation of 3-Aryl-2-cyanothioacrylamides. A $\left[2_{s}+4_{s}\right]$ Cycloaddition to give Substituted 3,4-Dihydro-2H-thiopyrans," Journal of the Chemical Society, Perkin Transactions, Vol. 1, 1978, 629-633.

[16] V. G. Brunton, M. J. Lear, D. J. Robins, S. Williamson and P. Workman, "Synthesis and Antiproliferative Activity of Tyrphostins Containing Heteroaromatic Moieties," Anti-Cancer Drug Design, Vol. 9, No. 4, 1994, p. 291309.
[17] B. Tornetta, G. Scapini, F. Guerrera and A. Bernardini, "Structure-Antibacterial Activity Relations of Arylthioamides. IV. Synthesis, UV Spectra and Tuberculostatic Activity in vitro of Some Arylvinylenethioamides," Boll. Seduta Accad. Gioenia Sci. Nat. Catania, Vol. 10, No. 5, 1970, pp. 353-363.

[18] V. Grinstein and L. Serina, "Cyanothioacetamide and Its Derivatives," Latvijas P. S. R. Zinatnu Akad. Vestis, Kim. Ser, Vol. 4, 1963, pp. 469-474.

[19] R. A. Mekheimer and R. M. Shaker, "Synthesis and Reactivity of 3-Alkylthio-5-Cyanomethyl-4-Phenyl-1,2,4-triazoles", Journal of Chemical Research, No. 2, 1999, pp. 76-77. doi:10.1039/a806842i

[20] K. Saito, S. Kambe, Y. Nakano, A. Sakurai and H. Midorikawa, "Synthetic Studies Using $\alpha, \beta$-Unsaturated Nitriles: A Convenient Preparation of 1,3-Benzothiazole Derivatives," Synthesis, No. 3, 1983, pp. 210-212. doi:10.1055/s-1983-30284 